\title{
Saphenous Vein Graft Aneurysm and Coronary Artery Disease: Case Report
}

\author{
Victor Rodrigues Ribeiro Ferreira ${ }^{1,2}$, Maria Christiane Valéria Braga Braile-Sternieri, ${ }^{1,2}$, Eliana Migliorini \\ Mustafa ${ }^{1}$, Giovanni Braile Sternieri', Sofia Braile Sabino', Cibele Olegário Vianna Queiroz ${ }^{1}$, Bethina \\ Canaroli Sbardellini ${ }^{1}$, Luiza Braile Verdi ${ }^{1}$, Idiberto José Zotarelli Filho ${ }^{1^{*}}$ and Domingo Marcolino \\ Braile $^{1}$ \\ ${ }^{1}$ Domingo Braile Institute of Sao Jose do Rio Preto (SP), Sao Paulo, Brazil \\ ${ }^{2}$ Faceres - Medical School of Sao Jose do Rio Preto, Sao Paulo, Brazil

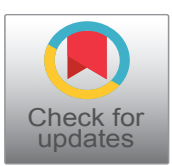

*Corresponding author: Idiberto José Zotarelli Filho, MSc, Ph.D, Domingo Braile Institute of Sao Jose do Rio Preto (SP), Rua Luiz Vaz de Camoes, 3111 - Vila Redentora, Sao Jose do Rio Preto - SP, 15015-750, Sao Paulo, Brazil, Tel: +55(17)98166-6537, ORCID id: 0000-0003-4328-1829

\begin{abstract}
Introduction: Despite a general reduction in the number of myocardial revascularization surgeries in recent decades, more than 150,000 are still performed annually in the United States. Early complications of venous graft use include an occlusion rate of up to $25 \%$ in the first year. The aneurysmal dilatation of the great saphenous vein, when used in aorto-coronary venous bridges, is rare and requires important care by the cardiology team.

Objective: This study aimed to present a case report on saphenous vein aneurysm in a patient with coronary artery disease and myocardial ischemia who was diagnosed by angiotomography of the coronary arteries.

Case report: The 68-year EDAV patient due to coronary artery disease received saphenous vein grafts. After the last angiotomography of the coronary arteries by computed tomography performed in 2019, May-21, aortic root ectasia, measuring $39 \times 40 \times 42 \mathrm{~mm}$ and Grafted Saphenous Vein Aneurysms (GSVA), and mural atheromatosis of the thoracic aorta were found.

Final considerations: GSVA may present in a heterogeneous way, but are more commonly discovered as an incidental finding in those patients with prior coronary artery bypass grafting. Therefore, there is a paucity of literature to help guide decision-making and the timing of catheter-based interventions.
\end{abstract}

\section{Keywords}

Coronary artery disease, Cardiac ischemia, Safena, Safene's aneurysm

\section{Introduction}

Despite a general reduction in the total number of myocardial revascularization surgeries in recent decades, more than 150,000 are still performed annually in the United States [1]. Arterial bypass ducts, particularly the left internal mammary artery, are frequently used and have been associated with better patency rates and clinical outcomes compared to patients treated without mammary artery graft [2]. However, the vast majority of patients undergoing myocardial revascularization surgery have at least one Saphenous Vein Graft (SVG) used as a bypass conduit. Early complications of venous graft use include an occlusion rate of up to $25 \%$ in the first year [3].

The great saphenous vein is usually used as a conduit in vascular derivations, and is considered, by most surgeons, the best and longest lasting arterial substitute in the infra-inguinal positions. Its degeneration and formation of true aneurysms are extremely rare $[1,3,4]$.

Aneurysmal dilatation of the great saphenous vein, when used in aorto-coronary venous bridges, is a rare event [2]. Most patients develop asymptomatically. They may appear as a pulsatile mass when the graft is in a superficial position. Like true arterial aneurysms, they

Citation: Ferreira VRR, Braile-Sternieri MCVB, Mustafa EM, Sternieri GB, Sabino SB, et al. (2019) Saphenous Vein Graft Aneurysm and Coronary Artery Disease: Case Report. Int Arch Cardiovasc Dis 3:023. doi.org/10.23937/2643-3966/1710023

Accepted: September 26, 2019; Published: September 28, 2019

Copyright: (C) 2019 Ferreira VRR, et al. This is an open-access article distributed under the terms of the Creative Commons Attribution License, which permits unrestricted use, distribution, and reproduction in any medium, provided the original author and source are credited. 
may present with compressive symptoms. If untreated, true aneurysms of venous graft tend to complicate with their rupture or even formation of fistulas with adjacent organs leading to potentially fatal frames [2].

Late complications include graft degeneration, intimal hyperplasia with resulting graft stenosis, and aneurysm formation [2]. Although degeneration and stenosis are associated with typical symptoms of cardiac ischemia, Grafted Saphenous Vein Aneurysms (GSVA) are generally asymptomatic and are often identified incidentally during imaging for other concerns. Those with symptoms may experience angina, symptoms of compression in the surrounding structures (ie cough), dyspnea, hemoptysis (fistula), orthopnea (hemothorax), or sudden death. Generally defined as a dilation greater than 1.5 times the reference graft vessel, the incidence of GSVA is largely unknown, with reports varying dramatically from as low as $0.07 \%$ to as high as $14 \%$. The management of the aneurysms was significant enough to justify that the intervention has been traditionally surgical. However, with the new use of several endovascular pathways [2].

In this sense, as a diagnostic test of this problem, we highlight Coronary Angiotomography (CAT) with important technical advances such as greater axial coverage (from $2 \mathrm{~cm}$ to $16 \mathrm{~cm}$ ) and better temporal resolution, allowing the CAT to become the imaging method noninvasive technique for the diagnosis of ar- tery aneurysms and saphenous vein grafts, with sensitivity and specificity of approximately 95\% [5].

Therefore, the present study aimed to present a case report on saphenous vein aneurysm in a patient with coronary artery disease and myocardial ischemia who was diagnosed by angiotomography of the coronary arteries.

\section{Case Report}

The patient EDAV, with 68-years old, due to coronary artery disease received saphenous grafts. After the last angiotomography of the coronary arteries by computed tomography performed in 2019, May-21, aortic root ectasia was measured, measuring $39 \times 40$ $\times 42 \mathrm{~mm}$ and GASV, as well as mural atheromatosis in the thoracic aorta, as shown in Figures 1, Figure 2 and Figure 3.

\section{Discussion}

The present case report showed through coronary artery angiotomography examinations that grafted saphenous vein resulted in aneurysmal alterations. The cause of this degeneration still remains unknown, being suggested by some authors as atherosclerotic or as a process of global dilatation of vessels in patients affected [1-3]. In other histopathological studies, proliferative and fibrotic lesions of the intima were noted, leading to weakening of the venous wall and, thus, favoring graft aneurysm formation [2].

In this sense, there is a substantial risk of complica-

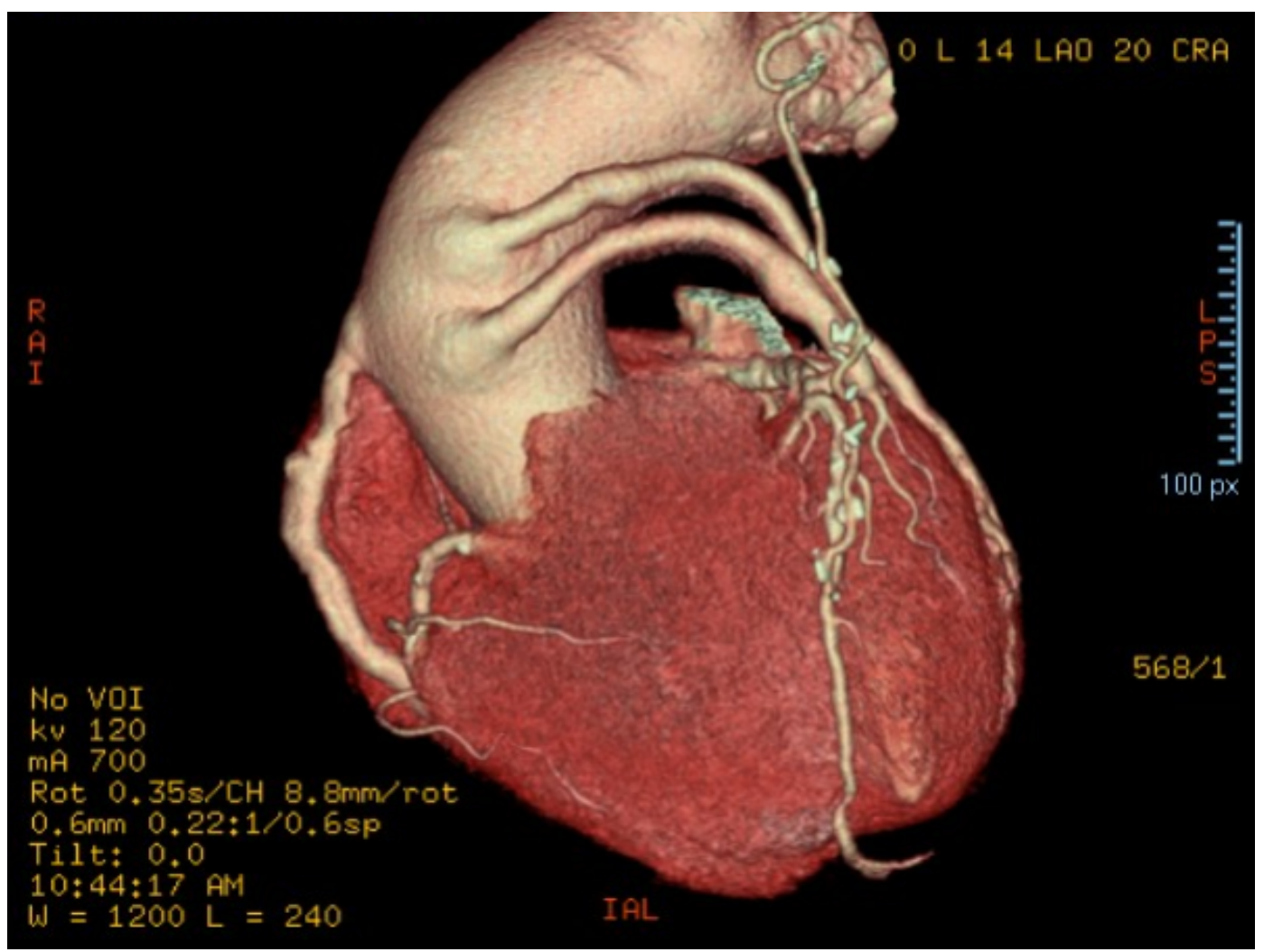

Figure 1: Angiotomography examination of the coronary arteries, showing the saphenous vein aneurysm grafted by the angle of observation 1 . 


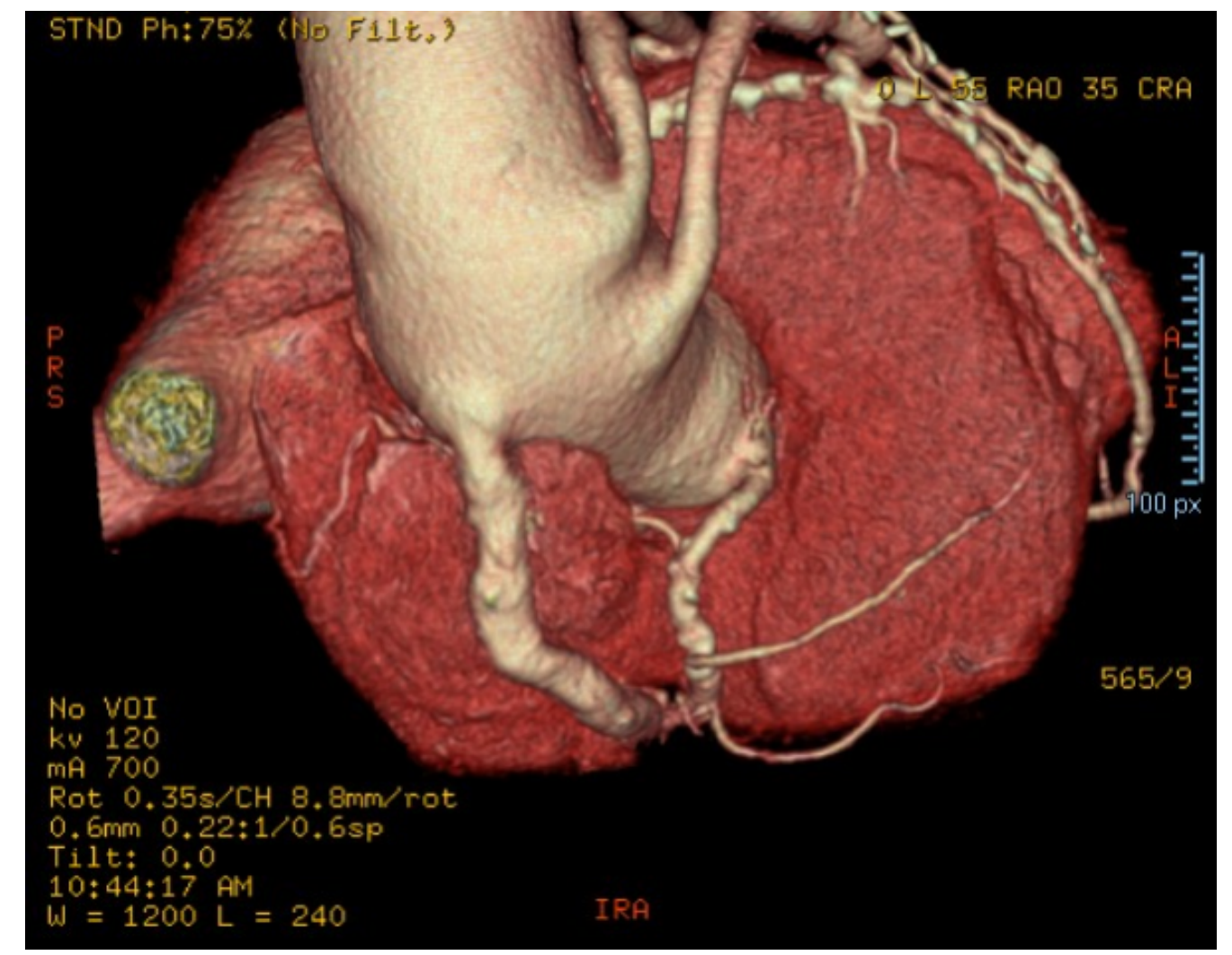

Figure 2: Angiotomography examination of the coronary arteries, showing the saphenous vein aneurysm grafted by the angle of observation 2 .

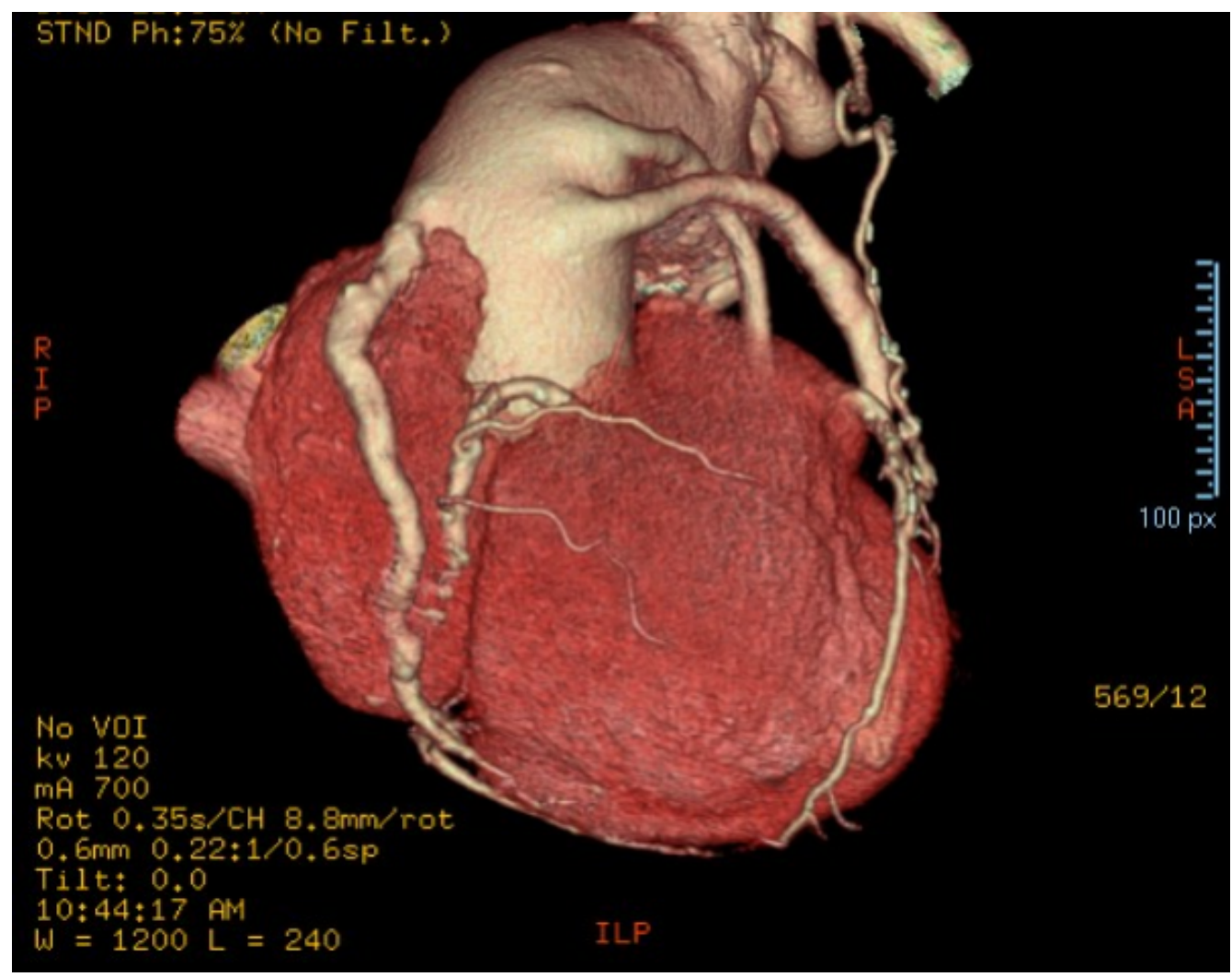

Figure 3: Angiotomography examination of the coronary arteries, showing the saphenous vein aneurysm grafted by the angle of observation 3 .

tions following saphenous graft, including rupture and death, so that surgical or percutaneous treatment may be considered, in particular, in symptomatic patients
[2]. One study highlighted three cases highlighting various options and considerations of percutaneous management, including stent placement, coil occlusion, and 
a combined approach to the use of a peripheral stent. Intervention within this patient population lacks large long-term population outcomes and, as such, should be performed with care by experienced operators [2].

Thus, aneurysms of saphenous vein grafts are rare but are potentially fatal and their ideal management is not clearly established. A case report study of GSVA that was successfully treated with surgical intervention, including aneurysmal resection and re-grafting [6]. The aneurysm detected 36-years after myocardial revascularization surgery was located in the proximal part of the grafted saphenous vein for the posterolateral branch; the left anterior descending coronary artery flow was limited due to compression of the left internal thoracic artery by the adjacent aneurysm. The site of the proximal anastomosis was reconstructed under deep hypothermic circulatory arrest using a pre-sewn vascular prosthesis patch with radial artery graft [6].

In this context, previous data demonstrated that aneurysms over $60 \mathrm{~mm}$ in diameter have a combined rate of mechanical complications, rupture, myocardial infarction and death above 50\% [7]. However, aneurysms less than $20 \mathrm{~mm}$ in diameter had a combined risk of complications approaching 35\%, making it very difficult to assess what is and is not a stable or unstable aneurysm. Certainly, once any complication has occurred which can be directly attributed to the aneurysm, intervention is a reasonable option [8]. Given the significant variability in the way, GSVA is diagnosed, at which point the diagnosis is made, and the most common presentation as an incidental finding during other medical care, data are lacking on any correlation between growth rate and risk of rupture $[9,10]$.

Percutaneous management was previously shown as a safe and viable option in a small series of cases $(n=33)$ [2]. The successful closure of a percutaneous approach can be considered with the placement of an aneurysm exclusion stent or with a coil embolism or Amplatzer implantation device (Abbott) for the occlusion of the aneurysm. There are no published data on large long-term population outcomes [2].

\section{Final Considerations}

The GSVA may present in a heterogeneous form, but are more commonly discovered as an incidental finding in those patients with prior coronary artery bypass grafting. Once identified, the risk of any complication, including death ranging from $33.3 \%$ in small aneurysms to $69.2 \%$ in aneurysms with more than $100 \mathrm{~mm}[2]$.
Therefore, there is a paucity of literature to help guide decision-making and the timing of catheter-based interventions. The choice of the intervention should be guided by the characteristics of the aneurysm, the venous graft and the relevant myocardial territory. Percutaneous intervention is a safe and viable option for the management of GSVA.

\section{Acknowledgements}

The work was supported by Domingo Braile Institute - São José do Rio Preto - SP, Brazil.

\section{Declaration of Potential Conflict of Interest}

The authors declare no conflict of interest.

\section{References}

1. Walters D, Patel M, Penny W (2019) Saphenous vein graft aneurysm: A case-based review of percutaneous management. Cardiovasc Revasc Med.

2. Matsuda Y, Nagasawa A, Koyama T (2018) Spontaneous rupture of an aortocoronary saphenous vein graft. J Card Surg 33: 99-100.

3. Milton Alves das NJ , Rafael CM, Catarina CA, Allison RF, Alexandre $P$, et al. (2011) Aneurysm of saphenous vein graft after arterial reconstruction: Case report. J Vasc Bras 10.

4. Barua A, Kaul P, Briffa N (2015) Giant vein graft aneurysm. J Card Surg 31: 102.

5. Gottlieb I, Bittencourt MS, Rochitte CE, Cavalcante JL (2019) Coronary computed tomography angiography takes the center stage and here is why. Arq Bras Cardiol 112: 104-106.

6. Yamamoto T, Saito S, Matsuura A, Miyahara K, Takemura $\mathrm{H}$, et al. (2017) Saphenous vein graft aneurysm repaired with radial artery graft pre-sewn vascular prosthesis patch. Heart Lung Circ 26: e1-e3.

7. Li M, Du XM, Jin ZT, Peng ZH, Ding J, et al. (2014) The diagnostic performance of coronary artery angiography with 64-MSCT and post 64-MSCT: Systematic review and meta-analysis. PLoS One 9: e84937.

8. Stocker TJ, Deseive S, Leipsic J, Hadamitzky M, Chen MY, et al. (2018) Reduction in radiation exposure in cardiovascular computed tomography imaging: Results from the prospective multicenter registry on radiation dose estimates of cardiac CT angiography in daily practice in 2017 (PROTECTION VI). Eur Heart J 39: 3715-3723.

9. Forbes J, Hunter A, Lewis S, MacLean S, Mills NL, et al. (2018) Coronary CT angiography and 5-year risk of myocardial infarction. N Engl J Med 379: 924-933.

10. Moss AJ, Williams MC, Newby DE, Nicol ED (2017) The updated NICE guidelines: Cardiac CT as the first-line test for coronary artery disease. Curr Cardiovasc Imaging Rep 10: 15.

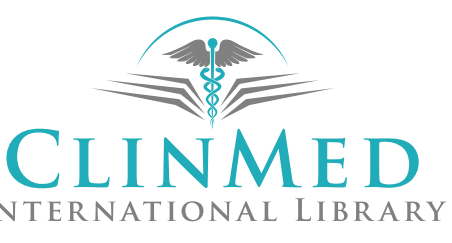

